\title{
The extent and effects of violence among psychiatric in-patients
}

\author{
C. Thomas, A. Bartlett and G. C. Mezey
}

\begin{abstract}
Actual and percelved safety of male and female in-patients in an inner-city psychiatric hosplital were examined. Using semi-structured interviews, 59 inpatients were asked to report on their direct experiences of physical or sexually threatening behoviour fowards them during their admission. Of the sample, $75 \%$ reported unwanted physical or sexual experiences: female patients were significantly more likely than males to report sexual harassment. Most incidents were not reported to staff and both staff and patients appeared to perceive the ward environment as safe desplte failly high levels of verbal and physical aggression. This study has implications for the way that 'violent incidents' in psychiatric hospitals are defined and recorded and raises questions about the provision of women-only space in hospltals.
\end{abstract}

A number of studies have documented a high incidence of in-patient violence in psychiatric hospitals (Health and Safety Commission, 1987; Haller \& Deluty, 1988; James et al, 1990; Aquilina, 1991). Most research has focused on the characteristics of the violence and of the perpetrators; the impact of such violence on patients' psychological and emotional health has tended to be neglected.

It has been suggested that formal incident reports often underestimate the incidence of assaults in the hospitals (Haller \& Deluty, 1988). Many minor assaults are unrecorded despite their potentially damaging effects on the victims or witnesses.

Little attention has been paid to the sexual victimisation of psychiatric in-patients. However, mentally handicapped and psychotic adolescents in adult wards are thought to be particularly vulnerable to sexual harassment (Gath, 1989). Higher rates of past sexual abuse and assault have been described in female psychiatric patients than a non-clinical population, which may make them particularly vulnerable to the abuse and exploitation (Palmer et al, 1993; Mullen, 1990).

Concern about the effect of integrating psychiatric wards on women's safety has recently been expressed. The MIND 'Stress on
Women campaign' (MIND, 1992) highlighted a failure on the part of psychiatric hospitals to protect, prevent and deal sensitively with allegations of sexual harassment and abuse of female psychiatric patients. Reported incidents involving sexual harassment of patients in psychiatric hospitals prompted the Public Policy Committee of the Royal College of Psychiatrists to issue a statement highlighting the issue (Gath, 1989).

This study was prompted by the growing number of media reports of sexual harassment of women patients and sexual assault on female psychiatric in-patients. The aim was to describe the victimisation experiences associated with psychiatric in-patients, as well as staff awareness and attitudes towards such incidents.

\section{The study}

A cross-sectional survey of patients and staff was conducted in a large London psychiatric hospital with a patient capacity of 450 . The sample was drawn from four acute admission wards, a closed supervision unit, a long-term ward for behaviourally disturbed patients and a rehabilitation unit. All patients in these wards on the days of the survey were included in the sample, with the exception of patients who were considered to be too ill to be interviewed.

Four semi-structured questionnaires were conducted by a male charge-nurse (MB). The remainder were conducted by a female psychiatrist (CT). Demographic details were recorded and diagnostic category as well as experiences of intimidation, threatened or actual physical or sexual assault by the patients over the past year of their admission, or for the duration of the current admission (Table 1). The interviewer made a separate rating on the validity of each patient's account at the end of the interview. This was based on considerations of the patient's mental state and whether allegations of sexual abuse had been a repeated feature of their mental illness in the 
past. Parents were specifically excluded if sexual allegations appeared to be an extension of delusional or erotomaniacal ideas.

Nursing staff, selected from the same wards as the patients, completed anonymous questionnaires which asked about their perception of patient safety and whether they had witnessed or were aware of any violent or sexual assaults on patients in the week prior to being interviewed. They were also asked to comment on whether their wards had a policy on sexual relationships between patients and if not, whether they thought there should be one.

Patients' nursing and medical notes, including incident forms, were examined for reports of assault or harassment.

\section{Findings}

\section{Patient results}

Characteristics of sample Fifty-nine patients completed the questionnaire out of a total of 151 in-patients on the wards surveyed. The high exclusion rate of patients reflected the fact that many patients were occupied in other parts of the hospital during the periods the researchers were present on the wards. All patients who were asked to participate in the study agreed to do so; this represented a compliance rate of $100 \%$. No patients were excluded on the basis of their claims appearing to be delusional or fictitious.

Twenty-eight $(48 \%)$ of the patients were female and $31(53 \%)$ were male. Forty-seven $(80 \%)$ were Caucasian. The length of time in hospital ranged from four days to 15 years with a mean stay of 29 weeks. Eleven patients had been in hospital in excess of two years.

Nature of victimisation Forty-two (71\%) patients reported some form of harassment by other patients (Table 1). Certain patients reported more than one category of victimisation of the same category on more than one occasion. Twenty-three (39\%) of the total sample had been hit at least once during their admission and a larger number had been threatened with violence or been verbally abused. Many patients had experienced more than one form of victimisation and on more than one occasion (Table 2). However, most patients reported a violent or threatening incident at less than monthly intervals.
Diagnostic category was not significantly associated with risk of being victimised.

There was no difference in the numbers of male and female patients who reported actual or threatened physical violence. Women were significantly more likely to report unwanted sexual comments or molestation than men; one third of the female subjects alleged such experiences. Two female patients alleged that they had been subjected to unlawful nonconsensual intercourse by male psychiatric patients in the hospital grounds.

Most of the reported 'sexual' incidents took place on the wards, or within the hospital rather than in the grounds. The majority of incidents fell into the category of unwanted sexual approaches, including repeated pressures for dates, requests to have sex. and offensive sexualised comments. Other incidents included being touched on the breasts or legs or being stared at by male patients and visitors in a way that they found disconcerting and intimidating.

Of 21 patients who reported sexual comments, sexual molestation or sexual assaults, three did nothing, nine ran away and one reacted aggressively. The majority of women did not report these experiences to staff.

In the case of two alleged rapes, both perpetrators were charged with rape; one charge was dropped on the basis of insufficient evidence. The other charge is currently under investigation. Both victims delayed reporting their experiences for at least 12 hours. A number of female patients were aware of these events having taken place, and felt their safety to be compromised.

Female patients were more satisfied than male patients with staff response to their reports of assault but were also more likely to feel unsafe in the wards. Half the females believed their level of safety to be the same as on admission, about one quarter felt more safe and one quarter less safe. Only $30 \%$ of females suggested that conditions on the wards could be improved by providing more nurses, tighter security, separate wards for men and women, excluding violent patients from general admission wards and segregating the washing areas.

\section{Staff results}

All nursing staff who were approached agreed to participate in the study. Of the 31 nursing staff interviewed, $38 \%$ were male and $62 \%$ 
Table 1. Number (and \%) individuals reporting victimisation experiences during acute admission, or over last year of long-term admission

\begin{tabular}{lcccc}
\hline & Total $(n=59)(n \%)$ & Male $(n=31)(n \%)$ & Female $(n=28)(n \%)$ & $p$ \\
\hline Harassment & $42(71)$ & $21(68)$ & $21(75)$ & 0.54 \\
Sexual comment & $16(27)$ & $5(16)$ & $11(39)$ & 0.05 \\
Molestation & $11(19)$ & $2 .(7)$ & $9(32)$ & 0.01 \\
Sexual assault & $2(3)$ & $0(0.0)$ & $2(4)$ & 0.13 \\
Shouted at & $33(56)$ & $17(55)$ & $16(57)$ & 0.88 \\
Other form of threat & $10(17)$ & $3(10)$ & $7(25)$ & 0.12 \\
Threat to be hit & $24(41)$ & $13(42)$ & $11(39)$ & 0.84 \\
Attempted to be hit & $16(27)$ & $9(29)$ & $7(25)$ & 0.73 \\
Has been hit & $23(39)$ & $13(42)$ & $10(36)$ & 0.62 \\
Satisfied with staff response & $9(15)$ & $2(7)$ & $7(25)$ & 0.05 \\
Previous sexual/physical assault & $18(30)$ & $7(23)$ & $11(39)$ & 0.16 \\
Feel safe on the wards & $41(70)$ & $25(81)$ & $16(57)$ & 0.05 \\
\hline
\end{tabular}

$P$ value from $\chi^{2}$ test

Harrassment: "have you experienced any unwanted or unpleasant physical and lor sexual experiences?": molestation: "has someone tried to touch you sexually when you did not want them to?": sexual assault: "has anyone actually done something sexual to you since your admission, even though you did not want them to?"

Table 2. Frequency of victimisation experiences, as percentage of total patients $(n=59)$

\begin{tabular}{lllllll}
\hline & $\begin{array}{l}\text { Sexual } \\
\text { molestation }\end{array}$ & Shouted at & $\begin{array}{l}\text { Threatened } \\
\text { assault }\end{array}$ & $\begin{array}{l}\text { Attempted } \\
\text { assault }\end{array}$ & $\begin{array}{l}\text { Physical } \\
\text { assault }\end{array}$ & $\begin{array}{l}\text { Sexual } \\
\text { comment }\end{array}$ \\
\hline Daily & 5 & 1 & 0 & 0 & 3 & 1 \\
2-3/week & 7 & 4 & 1 & 0 & 1 & 0 \\
1/week & 5 & 0 & 2 & 2 & 0 & 0 \\
\hline
\end{tabular}

female; $61 \%$ of the sample were staff nurses, $12 \%$ students, and $6 \%$ ward managers.

Thirty-eight per cent of staff had witnessed a violent or sexual assault during the previous week and $65 \%$ of staff reported being aware of other incidents. The majority of nursing staff $(75 \%)$ described themselves and patients as 'safe', although a smaller proportion thought that the patients felt 'safe' on the wards. There was no significant relationship between staff grade and perception of patients' actual safety.

\section{Nursing and medical records}

A total of 43 incidents were recorded in the medical notes, compared with 76 in the nursing notes. These incidents involved 14 female and 17 male patients. The majority of reports related to violent or disturbed behaviour by patients rather than to their experiences of victimisation or harassment. The discrepancy in number of incidents recorded did not necessarily correlate with the seriousness of the incident, e.g. nursing notes recorded a patient who was found attempting to have intercourse with a female patient, as 'sexually disinhibited'. This incident was not referred to in the medical notes.

\section{Comment}

The finding that $71 \%$ of the patient sample had experienced harassment of some form is higher than in previous studies (Ruben et al, 1980; Haller \& Deluty, 1988) but is in keeping with recent research citing an increase in assaults in psychiatric hospitals (James et al, 1990; Aquilina, 1991). It suggests that the past emphasis on staff victimisation may have neglected the population experiencing the greatest trauma, namely patients.

Although patients were asked about assaults or threats from other patients, few (16\%) spontaneously identified male staff as their assailants. The design of this study did not allow us to explore these experiences further; however it is possible that certain techniques used by nursing staff to restrain patients physically could be misinterpreted as an assault. 
Various reasons have been postulated for the apparent increase in ward-based violence: inadequate resourcing of the health services resulting in understaffed wards, an increased use of temporary nursing staff (James et al, 1990); the discharge of more manageable patients from hospitals in keeping with the policy of deinstitutionalisation, leaving younger, more disturbed patients in the wards, an increasing number of readmissions and involuntary admissions; mixtures of patients with diverse psychopathology (Haller \& Deluty, 1988). It may be that psychiatric hospitals have always been unsafe, but that only recently has it become acceptable to discuss such issues openly.

The high proportion of patients reporting victimisation experiences in response to direct questioning contrasts with the relatively few incidents reported in nursing and medical notes. Incidents recorded in medical and nursing records are weighted towards the more serious physical assault and focus on the perpetrator rather than the victim. This suggests that patients' victimisation experiences, specifically the more subtle forms of victimisation and intimidation, e.g. sexual harassment, are unrecognised or not considered important enough to record.

A notable finding was the difference in victimisation experiences between males and females: women experienced a significantly higher incidence of minor and serious sexual victimisation. Despite being experienced as offensive and distressing by the women, most of these incidents were unreported. This finding is in keeping with the under-reporting of sexual assault in the community (Kilpatrick $\&$ Best, 1990). The reason given by most patients for not reporting was that the perpetrators were mentally ill. The apparent acceptance of these experiences could reflect the women's sense of powerlessness outside as well as within hospital. Like women in the community, they may be too ashamed or embarrassed to report these experiences.

The majority of patients and staff intrerviewed perceived their environment as safe despite most of them being aware of, witnessing or experiencing harassment of some form. One explanation of this mismatch between perception and reality is an increasing tolerance to regular episodes of violence operating on a background of tension, arguments and conflict which become accepted as the norm over time.
It is difficult to explain the discrepancy in the recording of 'incidents' between the medical and nursing records. Such discrepancy may reflect nursing judgement about the significance of the incident and its relevance to the overall management of the patient and therefore not communicated. The information may be communicated to medical personnel but not recorded. Failure to communicate individual incidents either between nursing staff or from nursing staff to medical personnel may lead to a series of incidents going unremarked. It may be possible to improve the accuracy of recording by direct questioning about untoward incidents in ward rounds and case conferences. An alternative explanation is the 'normalisation' of sexually aggressive behaviours by psychiatric patients, so that such experiences do not evoke the same level of outrage as would be expected if perpetrated against a less stigmatised group of individuals. Whatever the cause, this discrepancy is a cause for concern, as it prevents investigation and corrective action.

Staff nurses tend to have more frequent face to face contact with patients than do higher professional grades and thus may be more aware of patients' daily experiences; this could explain their higher level of concern about patients' safety, which is consistent with previous studies (Health and Safety Commisson, 1987).

At the time of conducting this research there was no hospital policy on sexual relationships between patients or guidelines in the event of alleged sexual assault. Payne (1993) has commented on an apparent discomfort and reluctance to address this important issue, which he says is reminiscent of Victorian attitudes. Policies should respect patients' rights to consensual sex. but also ensure the safety of individuals who, as a result of illness, become involved in sexual relationships they may later regret. Subotsky (1993) suggests that counselling education and training of staff in this area is important.

The question arises as to whether patients are more at risk of victimisation in hospital than outside, or whether the risk of victimisation in hospital is simply a reflection of socio-cultural factors that reflect high crime rates generally. It is possible that a similar study carried out in an area of low recorded crime would yield different results. These results do not necessarily suggest inadequate practice or policies in the hospital under 
study, but may be a reflection of the sociodemographic characteristics of the hospital's catchment area.

This study is limited by its small sample and a selected number of wards. Nevertheless, it highlights potential hazards of admission to psychiatric hospitals, in particular the vulnerability of female patients in mixed sex wards. The study raises questions about the wisdom of integrating the sexes in psychiatric facilities, without consideration of the potential risk involved and patients preferences. These results suggest that integration of the sexes may have more disadvantages for women than for men.

A practical suggestion arising from the study would be the institution of a patients' advocacy service, which would be independent from hospital management and could act as a source of advice and support for victims of physical or sexual violence. Hospitals may wish to consider providing women-only spaces in wards and the segregation of male and female patients in certain circumstances, recognising the importance of giving patients choice about the environment in which they receive care and treatment.

\section{Acknowledgements}

The authors would like to thank the nursing, medical and management staff of the hospital surveyed for their permission to carry out this study, and their cooperation. We also thank our colleagues, Ann Backhouse and Max Bachmann for their assistance in statistical analysis, Sue Cooke, and Tom Fahy for editorial comments.

\section{References}

AQuiuNA, C. (1991) Violence by psychiatric in-patients. Medicine, Science \& the Law, 31, 306-312.
GATH, A. (1989) Statement on abuse and harassment within psychiatric hospitals. Psychiatric Bulletin. 13. 461-462.

HALLER, R. M. \& DELUTY, R. H. (1988) Assaults on staff by psychiatric in-patients. A critical review. British Journal of Psychiatry, 182, 174-179.

HealTH AND SAFETY COMmission (1987) Health Services Advisory Committee Violence to Staff in the Health Services. London: HMSO.

James, D. V., Fineberg, N. A., Shah, A. K. \& Priest, R. G. (1990) An increase in violence on an acute psychiatric ward. A study of associated factors. British Joumal of Psychiatry. 166. 846-852.

KILPATRICK. D. G. \& BEST, C. L. (1990 April) Sexual assault victims: data from a random national probability sample. Paper presented at the meeting of the Southeastern Psychological Association. Atlanta.

MIND (1992) Stress on Women Campaign. Campaign Briefing 2: An end to sexual harassment and abuse in mental health settings. Mind Publications.

MuLLEN, P. (1990) The long-term influence of sexual assault on the mental health of victims. Joumal of Forensic Psychiatry, 1, 13-34.

Palmer, R. L., Coleman, L., Chaloner, R., Oppenheimer, R. \& SMrT, J. (1993) Childhood sexual experiences with adults. A comparison of reports by women psychiatric patients and general practice, attenders. British Journal of Psychiatry, 163, 499-504.

PAYNE, A. (1993) Sexual activity among psychiatric inpatients: International Perspectives. Journal of Forensic Psychiatry. 4, 109-129.

Ruben, I., Wolkon, G. \& Yamamoto. J. (1980) Physical attacks on psychiatric residents by patients. Journal of Nervous and Mental Disease, 168, 243-245.

SUBOTSKY, F. (1993) Sexual abuse in psychiatric hospitals: developing policies to aid prevention. Psychiatric Bulletin. 17, 274-276.

C. Thomas, Senior Registrar in Child and Adolescent Psychiatry, Bristol Children's Hospital, St Michael's Hill, Bristol BS2 8BJ; A. E. A. Bartlett, Clinical Research Fellow, Section of Forensic Psychiatry: and *G. C. Mezey, Consultant Forensic Psychiatrist, Section of Forensic Psychiatry, St George's Hospital Medical School, Jenner Wing, Cranmer Terrace, London SW17 ORE

\section{*Correspondence}

